\title{
Two types of part-time registrar training in psychiatry
}

\author{
Erik van den Brink and Anja Sanders
}

\begin{abstract}
Uttile has been published by Junior trainees of their experience of part-time training. This paper discusses two cilferent arrangements of flexible training at registrar level based on the personal experience of a marrled couple where both partners wished to combine poychiatric training with chlldcare. Job-share by working alternate periods of $\mathrm{s} x$ months is compared with being in separate trexible training posts as super numerary registrars.
\end{abstract}

Recent publications in the Psychiatric Bulletin on part-time training in psychiatry have focused on the experience of senior registrars, particularly in child and adolescent psychiatry (Gath, 1988; Talbot, 1993). The survey by Routh (1991), however, indicates that there is considerable interest in part-time training among junior trainees. We think it is useful to share our experience of flexible training as registrars, especially because we are in a position to compare two different arrangements. We are a married couple and when our first child was born we both wished to pursue our training as well as play a satisfactory role in childcare. Having completed one year of full-time training as senior house officers we agreed to share one whole-time registrar post and work for alternate periods of six months. We worked in this way for three and a half years and meanwhile our second child was born. In August 1992 we were accepted on separate flexible training contracts with Yorkshire Regional Health Authority. Since then we have been working as supernumerary registrars for five sessions a week each, avoiding overlap, so that at all times one parent is available for childcare. What follows is our experience of these two types of part-time training.

\section{Job-share: alternate periods of sir months}

In our situation there were two obvious methods of sharing the work, either by splitting jobs in half and doing five sessions each, or by working for alternate six-monthly periods. The former method, much more difficult to arrange, would have meant being available for only three sessions a week during the times we attended the day-release course at Leeds University. We therefore chose working for alternate periods as it meant we had the full responsibility of a whole-time trainee in a six months' attachment. This helped us to gain confidence in the earlier stage of training. We had no difficulty obtaining educational approval from the College as we were already on an approved scheme. The arrangement fitted in effortlessly with the existing system of six-monthly rotation and was fully acceptable to colleagues and patients. It did not disrupt the routine on wards as dividing the work in half would have done. At home the situation was equally simple because of the traditional divide with one partner going to work and the other being at home, although the sexes were reversed at times.

There were also disadvantages to this way of working. During the periods at home we felt very much out of touch with work and training. This was in part helped by each of us continuing the academic course during the periods we were off work. There was also the problem of how to continue seeing patients for longer-term psychotherapy but this was resolved by the creation of honorary contracts. Both arrangements required the unpaid investment of time as well as the assistance of a childminder. Another disadvantage was that we could only sit MRCPsych examinations once a year, as one needs to be in an approved post at the time of taking each of them. More importantly considerable adjustment was required from every family member during the abrupt transitions every six months. Although our son seemed to adapt well, it must have been 
confusing for him to see his parents exchange roles. It took some effort from ourselves to change focus from the world of working adults to that of pre-school children, and vice versa. As a result we desired a more harmonious way of combining training with childcare.

\section{Supernumerary scheme}

When we had completed the day-release course, working five sessions a week became more attractive to us. Rather than doing this as described above by job sharing a whole-time post, we were pleased to be accepted on individual contracts for supernumerary posts, which are separately funded and allow one to work across the whole region rather than within the limits of a particular rotational scheme. As most consultants welcome an extra part-time trainee, opportunities to meet our individual interests and training-needs increased considerably. This does not imply that we can do whatever we wish as each attachment needs prospective educational approval from the College and the Regional Postgraduate Dean, and must include on-call commitments. The present arrangement, however, promotes continuity of work, training and parenting, avoiding the six-monthly disruption. Attachments can easily be extended beyond stx months, which is valuable for gaining experience in psychotherapy and the longer-term management of patients.

Disadvantages of working only five sessions a week are particularly obvious in relation to avallability for urgent assessments and continuity of care for in-patients. Good communication with colleagues is essential, especially with the whole-time trainee on the same team.

Equally important is adequate communication with nursing staff to avoid confusion about which doctor is looking after which patient, and to make clear when one is available to review patients and for other ward work. In posts with mainly out-patient work, such as in child and adolescent psychiatry, half-time placements cause fewer problems. In adult and old age psychiatry. placements at day units and community mental health centres can be more acceptable.

Considerable planning is necessary to ensure that our timetables do not overlap and that we are both adequately involved in case conferences and journal clubs. Timemanagement can be a significant problem as a relatively large proportion of time is spent in ward-rounds or other meetings. In attempts to keep up with clinical work, time set aside for study and research easily erodes, and it can be difficult to maintain contact with one's peers. Finding time for supervision with the consultant can be equally difficult. Often supervision may be shared with the wholetime trainee, although this is not necessarily a disadvantage as it can mutually enhance learning.

Before starting on the present scheme we wondered whether work had to be 'stolen' from the whole-time trainee. Our experience, however, is that the contributions of a supernumerary colleague are generally appreciated and enable the full-time trainee to do fewer tasks more thoroughly, which can be more rewarding. Our additional manpower proved particularly useful in some areas of psychiatry in which medical input was relatively scarce, such as community mental health care for the elderly and rehabilitation.

\section{Conclusions and comment}

Both ways of part-time training have advantages and disadvantages and it depends on one's personality, domestic situation and training needs which suits one best. We found working for alternate sixmonthly periods was good in the earlier stage of training as one is exposed to a full dose of clinical experience which enhances confidence. It is the easiest to arrange, does not disturb the existing system in any way, but can be rather disruptive on the home front. The flexdbility and wider range of training opportunities of the supernumerary scheme became increasingly attractive to us as we advanced in our training.

We feel that the training we received has been of a similar quality to that of a full-time trainee. So far, we have not experienced a great deal of prejudice from working part-time, although this is more likely to happen in a supernumerary post than in a job-sharing situation. We were occasionally confronted with ignorance among some colleagues about childcare being an easy option. It is a rewarding experience but can be as intensive and demanding as work. Our initial hope that domestic tasks could be combined with revision for exams proved unrealistic, especially since the birth of our second child.

In Routh's (1991) sample of full-time junior trainees in psychlatry, $25 \%$ had in the past been wanting to work part-time but had been 
unable to do so. We were fortunate in obtaining such posts and in recetving support from consultants and clinical tutors to realise our plans. Trainees wishing to work part-time should seek advice from the Regional Postgraduate Dean and make sure that their proposed scheme meets the College's prospective approval. It should be possible to arrange some sort of job-sharing if there are two trainees wishing to work part-time. Being a couple is probably an advantage as there will be fewer conflicting interests and it is less likely that one trainee will suddenly want to move. Supernumerary registrar posts are not advertised and one should check availability with regional health authorities. The common view that part-time posts are for women only has probably little to do with the attitude of employers but perhaps more with reluctance among male doctors to enlarge their roles in domesticity. At the time of writing, however, two out of the four supernumerary part-time registrars in Yorkshire are men!

The advantages of part-time trainees to the NHS have been recognised previously (Livingston et al, 1988). Part-time training clearly benefits family-life but the experience of childcare is also highly relevant to the practice of psychiatry. We hope that the
College will actively promote flexdbility in training and careers for both women and men.

\section{Acknowiedgements}

We are grateful to Dr P. C. W. Bowie and Dr D. $J$. Thompson for their comments.

\section{References}

GATH, A. (1988) Part-time senior registrar training in child and adolescent psychiatry. Bulletin of the Royal College of Psychiatrists, 12, 368-370.

LIVINGSTON, H. M., OGELTHORPE, D. \& ROBERTSON, S. (1988) Part-time senior registrar training in psychiatry. A feasible option? Psychiatric Bulletin, 12, 523-525.

RouTH, C. P. (1991) Part-time training in psychlatry: what trainces want. Psychiatric Bulletin, 15, 614-615.

TALBOT, R. (1993) Part-time higher training in child and adolescent psychiatry. Psychiatric Bullettr, 17. 665-666.

*Erik van den Brink, Registrar in Psychiatry, Ingrow Centre for Community Mental Health, 200 South Street, Keighley BD21 1BB; and Anja Sanders, Registrar in Child and Adolescent Psychiatry, Hillbrook Child and Family Unit, Mayfield Road, Keighley BD20 6LD

"Correspondence

\section{Prince who?: the influence of the mass media on elderly people}

Rohul Roc examines the role of the Royals in diagnosing dementia.

The recent debate at the Liberal Democrats' Conference in Brighton about a future 'Republic of Britain' may have caused some disquiet among fervent monarchists. No doubt it will also have raised some alarm in the ranks of the current elderly population, in whose hearts the Royal Family appears to hold a very special place.
In screening and diagnosing dementia, for instance, the acquisition and retrieval of recent information is tested by assessing knowledge of current, including royal, affairs. During a recent research project Cambridge residents aged 81 and over were interviewed using the 'CAMCOG', the section of CAMDEX assessing cognitive function. As part of this, the question "What is the name of the present King/Queen?" is followed by "Who will follow him/her?". Out of the 123 subjects interviewed, $17 \%(n=21)$ did not know the 